\title{
Research on the Informatization Strategy of Civil Aviation Freight Transport Enterprises Based on Core Competence
}

\author{
Dong Wang
}

Sanya Aviation \& Tourism College, Sanya, Hainan, 572000

Keywords: Informatization strategy; civil aviation; freight transport; core competence

\begin{abstract}
This paper first analyzes the industry of air cargo. Through the analysis of the model of Porter, this paper discusses the main risks that China's air cargo enterprises face and the risk countermeasures based on information technology. At the same time, it discusses information of air cargo enterprises through information theory to clarify that information construction is the core competitiveness of air cargo enterprises.
\end{abstract}

\section{Introduction}

With the globalization of air transportation, the marketization of product sales and the increase of air traffic volume, the competition among air transport companies has become increasingly fierce. This not only brings opportunities for the development of the civil aviation industry, but also requires air transport management and management methods to adapt to the market. China's continuous high-speed economic growth has made China an internationally recognized country with rapid economic development in the 21st century. Air transport industry is still regarded as a "sunrise industry" in China. This advantage does not exist in most countries. After China's accession to the WTO, China is facing increasing pressure from the "open sky". For the Chinese civil aviation industry, this is both a chance for integration into the world aviation alliance and a challenge that may be squeezed and eaten by its opponents.

Information technology plays an important role in the development of air cargo transportation. Looking at the development process of the air cargo information system in the world, we have experienced the process from supporting the internal operations of enterprises to supporting the interactions among enterprises, from supporting daily operations to supporting value-added services. The scope of coverage of the system has become wider and wider, and the system has become more functional. The more comprehensive, the more complex the information technology used, and bring more and more value to air cargo participants.

According to the coverage of the air cargo information system, its development can be divided into five stages: the first stage, manual processing. Before using the information system, the air cargo industry can only manually process large amounts of documents and manually transfer air cargo related information. The entire process has low efficiency and high error rate, which hinders the development of the air cargo industry. The second phase, internal automation. Airlines, cargo terminals, and large freight forwarders have developed or purchased internal information systems in order to improve internal operational efficiency. With the development of information technology, these internal information systems are constantly improving and improving. Taking the airline system as an example, from the initial PO4 system to the later FAST and USAS Cargo systems, it has evolved to today's CHAMP, Super Cargo and other systems. Its functions have expanded from the initial cargo management functions to the current ULD (Air Transportation). The functions of the container-loader (ship) loading, cargo management, cargo tracking, query, and revenue management functions are continuously developed and improved. The third stage is the integration of aviation logistics chain. With the improvement of the internal information system of air cargo related parties, the information interaction between the parties has become the bottleneck in the air cargo flow, and a system for supporting information exchange between enterprises has emerged, including the cargo space trading system and the trading system. The cargo space trading system provides an electronic solution for the cabin booking business between airlines and freight 
forwarders. The trading system provides a standardized electronic way for information transmission between participants in the aviation value chain and government departments. With the continuous improvement of information systems integration between enterprises, the coverage of the system is becoming wider and wider, and the operational efficiency of the entire aviation logistics chain is improved. The fourth stage, supply chain integration. At this stage, the aviation logistics information system covers the entire supply chain. Information systems such as FedEx, UPS, DHL, and other major integrated service providers worldwide. These integrated service providers not only provide users with a full range of aviation logistics transportation services, but also participate in the supply chain management of shippers/consignees. Their information systems must not only support the entire air cargo service, but also assist the shipper/consignee supply chain. Management, which has been extended beyond the aviation logistics chain, has increased the efficiency of the entire supply chain. The fifth stage is the integration of intelligent supply chain. With the continuous application of newer and more advanced information technologies, the aviation logistics information system will be further developed and the parties involved in aviation logistics will be more closely integrated. Some intelligent information technology solutions such as advanced revenue management tool systems, customer automation services, supply chain management/third-party logistics solutions are being or will be gradually integrated into aviation logistics information systems to form a new generation of intelligent supply chain integration. system.

\section{Analysis of Development Status of Air Cargo Information in China}

At the beginning of the establishment of civil aviation, China was still under a planned economic system and all air cargo operations depended on manual operations. Later, driven by the market economy, China's air cargo business has developed rapidly. The freight business has also been supported by computer and other auxiliary equipment. In 1994, the Civil Aviation Information Center of China introduced the FAST4 centralized freight handling system of Alitalia, which provided cargo hosting services for China Southern Airlines, Yunhang Airlines, Northwest Airlines and certain airports. This is the first time China has introduced relevant information technology. Soon, SITA's SuperCargo cargo host system also landed in China and occupied two markets, Air China and China Eastern Airlines. The competition in China's air cargo information system has become fierce. The freight processing system during this period was dominated by centralized host processing. This mode of operation is stable, has strong processing capabilities, and can also achieve partial sharing of data. Because the freight processing system runs on mainframes, the program development and operation and maintenance are difficult, so the host system must also require special lines to connect, the system running speed is limited by the network conditions, often appear disconnected phenomenon; In addition, the host freight system instruction operation is complex, And the implementation costs are high. The general agent can not afford it, and can only continue to use manual operations. With the development of freight business, the demand for personalized transportation has obviously increased. The host freight system cannot meet the development needs of air cargo in China.

The rapid rise of the open platform and the wide application of new technologies have provided strong support for the innovation of China's air cargo information system. The local freight handling system under the open platform has gradually emerged. At that time, the main representative work was Tianxinda Information Technology Co., Ltd. (The following is referred to as the "Delivery Operation Processing System" (CFPS) introduced by Tianxinda and China Tang's Tangyi system. Many airlines and airports have used such systems and achieved good results, meeting the needs of China's air cargo development at that time. The open platform's local freight processing system has a high degree of flexibility, can be easily adjusted according to the needs of users, deployment and implementation are also very convenient, and the processing speed is very fast. However, for the entire industry data, the phenomenon of information islands is serious and data exchange is difficult, so it cannot be widely used. 


\section{Analysis of Informatization Strategy of Civil Aviation Freight Transport Enterprises}

Improve information system application management level information. The information system can be connected through a variety of networks to realize remote control. Under the Internet application, the system can easily achieve global synchronization and form a unified operation platform. The information system is built to better serve internal and external customers. With the development of new services and new requirements, the existing businesses are optimized and reorganized, and the existing processes are improved and improved, making the entire process more accurate and smooth. Fast. Raising the level of automation in daily operations and accelerating the efficiency of information processing are important technical means for improving the efficiency of aviation services and the quality of aviation services. Strengthen the development and application of IT technology. Accelerate the application of information technology in the entire process of air cargo development, develop Internet-based application technologies, wireless Internet access, and real-time tracking of parcels, and apply information technology to the entire process of freight transportation, such as cargo sorting, storage, and tracking. The air cargo information system can run on a variety of operating platforms, not limited by the network and hardware, can be connected and operated through the browser and smart client, can automatically download and update the system, eliminating the manual maintenance of the client. The development customer in real-time inquiries terminal and business self-service, quality feedback and other information service projects, and gradually promote to mobile phones and other smart mobile terminals to fully enhance the customer experience. Take the Hong Kong International Airport Super Terminal 1 as an example. The station is investing 240 million Hong Kong dollars in the development of a new generation of cargo management system COSAC-Plus, which can provide warehousing management and cargo tracking and consulting services, linking customs, airport management, aviation With 4,000 users including companies and freight forwarders in 30 countries, the system handles more than 1 million transactions a day. The electronic information platform functions of the Hong Kong airport are already quite sound, but they continue to invest in system upgrades and improve service levels and service capabilities through IT technology. Hong Kong Airport was named the most convenient cargo airport and became the busiest freight hub and transshipment center in the Asia-Pacific region. One of the reasons for its success was to rely on first-rate electronic information technology.

Standardization of information will effectively support business-to-business operations such as business settlement, capacity allocation, service tracking, and quality control, as well as data exchange, integration, and sharing of the entire air cargo chain, thereby improving transfer efficiency, reducing transit costs, and reducing operations. Risk. At present, the standardization and application of information in the freight industry in China is not extensive enough, and a unified information service standard and technology application standard for related industries must be established. The first is to combine the information standards and service specifications of international freight transport, study and formulate air cargo standards that are in line with international standards according to the characteristics of China's air cargo market, and actively promote some of the information standards of the International Air Transport Association, such as the electronic freight system with Cargo 2000 as its core. The use of service standards in the industry; the second is the use of technical means, the use of international standardization operations design in the construction of information systems, follow the business standards specified by IATACargo2000, have detailed provisions and controls for each business point, ensure the standardization of operations and data globalization. It also unifies information exchange standards among various systems in the industry, realizes cross-departmental and cross-industry freight system information exchange, and further integrates freight resources. The development of the freight industry is inseparable from the construction of sound laws, regulations and systems and policy guarantees. It is necessary to speed up the pace of legislation and establish a sound legal and regulatory system for the development of freight transport. Further learn from the relevant regulations and standards of the international freight industry, expedite the sorting and formulation of relevant laws and standards in China, especially the coordination and harmonization of laws and regulations for different modes of transportation, and formulate, revise and improve related 
regulations and standards in a timely manner.

E-freight adapts to the development direction of the global trade environment. The United Nations and the World Customs Organization are developing towards a paperless global trading environment. Some countries' customs have required accurate manifest information before the arrival of flights. Some exporters and importers require The network tracks cargo information in a timely and accurate manner. E-freight can respond to these requirements, and it can also reduce costs and improve services, greatly improving the efficiency of airline cargo handling and enhancing its competitiveness with other modes of transport. E-freight has become an inevitable trend in the development of air cargo. At present, domestic air cargo companies have strengthened the application of e-freight. China Cargo Airlines and China Southern Airlines took the lead in launching the e-freight order. In 2010, China Cargo Airlines achieved international and domestic round-trip electronic cargo. China Southern's domestic e-freight project received the IATA headquarters certification and was awarded the "China's first domestic IATA domestic e-Cargo Airlines" certificate in June 2010. It became the first in the Mainland and the 19th worldwide Cargo 2000 in May 2014. Full member airline. CNAC conducted a research report on the "Avionics Information Platform Information Platform" soft project and completed the first phase of the information platform construction.

\section{Conclusion}

With the ever-changing information technology, the traditional management methods of enterprises have lagged behind the development of the times. A large number of forward-looking entrepreneurs have realized the importance and urgency of informatization for the development of enterprises, and they have also realized the direct and indirect benefits that informatization brings to enterprises. Therefore, we must change concepts, change economic systems, change traditional thinking methods, understand and understand the knowledge economy, and actively think about new concepts such as where companies can create value, how to obtain value, and how to find value in the fierce market competition. , is gradually being accepted by modern entrepreneurs, and has been embodied in practice. This is to make full use of advanced microelectronics, computer communication technology, network technology, and software technology combined with traditional enterprise technological advancement and technological transformation to make production management, equipment update, resource allocation, and market services a series of business plans at any time. Adjust to the best condition.

\section{References}

[1] Weng Liang, Tian Lin. SWOT Analysis and Strategic Choice of Air Cargo Enterprise Informatization Construction [J]. Air Transport Commerce, 2007, 7(5): 32-34.

[2] Zhao Tiejun. Development of Air Cargo Information System in China [J]. China Civil Aviation, 2005, 6(12):69-70.

[3] Luo Jun. Implementing the Strategy of Strengthening Civil Aviation and Advancing the Construction of Freight Tracking Platform in Logistics Informatization[J]. Air Freight Commerce, 2010, 10(18): 4-11.

[4] Yang Liu. Design and Implementation of Shuangliu International Airport Freight Information Management System [D]. Chengdu: UESTC, 2013: 1-85.

[5] Li Yongqi. The direction of innovation and development of domestic air cargo[J].China Civil Aviation,2010,11(7):27-28. 